\title{
Evaluation, Awareness, Practice and Management of Cold Chain at the Primary Health Care Centers in Coastal South India
}

\author{
Rao S', Naftar $S^{2}$, Baliga $S^{3}$, Unnikrishnana $B^{4}$ \\ 'Dr. Suchetha Rao, MBBS, MD, Associate Professor, Department of Paediatrics, Kasturba Medical College, Mangalore, \\ Manipal University, India, ${ }^{2}$ Dr. Sheikh Naftar, MBBS, MD, Consultant Paediatrician, St. Sebastein Hospital, Cherupuzha, \\ Kerala, India, ${ }^{3}$ Dr. Shantharam Baliga, MBBS, MD, Professor and HOD Department of Paediatrics, Kasturba Medical College, \\ Mangalore, Manipal University, India, ${ }^{4}$ Dr. Unnikrishnan B, MBBS, MD, Professor and HOD Department of Community \\ Medicine, Kasturba Medical College, Mangalore, Manipal University, India.
}

Address for correspondence: Dr. Suchetha Rao, E-mail: suchethasr@gmail.com

\begin{abstract}
Introduction:Vaccination is one of the most effective disease prevention strategies and potency of vaccines is dependent on effective management of cold chain at all levels of vaccine handling. The objective was to assess the status of cold chain at the primary health centers and to assess the knowledge and practices of medical officers at these centers regarding cold chain management. Materials and Methods: This cross sectional study was conducted at 70 primary health centers of Dakshina Kannada District of Coastal South India. Cold chain equipment and maintenance process was noted following direct observation on uninformed visits. Data regarding the knowledge and practices of cold chain management was obtained by interviewing the medical officers using structured pretested questionnaire. Results: Ice lined refrigerators and deep freezers were available in 69 (98.6\%) and 67(95.8\%) of centers. Dial thermometer was present in all the centers. Cold boxes, frozen packs and automated voltage stabilizers were available in 68(97.2\%) centers. Improper vaccine storage was observed in 7 (10\%) centers. Majority of medical officers had knowledge and correct practices in fields like ideal equipment, OPV administration, vaccine requiring diluents but only 47 (61.8\%) medical officers had correct practice of defrosting the deep freezers. Conclusions: The availability of equipment is near universal. Improper vaccine storage practices and poor knowledge in some fields of cold chain management may adversely affect the quality of administered vaccine. Relevant training for those handling the cold chain is recommended.
\end{abstract}

Key words: Cold Chain, India, Primary health center, Temperature monitoring

\section{Introduction}

V accine preventable diseases like polio, measles, and hepatitis are major causes of morbidity and mortality among children in developing countries ${ }^{1}$. Vaccination is one of the most effective disease prevention strategies when implemented properly across all sections of the at-risk population. Immunization against a disease is achieved only if a potent vaccine is administered. The system of transporting, storing and distributing vaccines in a potent state at the recommended temperature from the point of manufacture to the point of use is the cold chain. Vaccine potency once lost cannot be restored. The cold chain remains a highly vulnerable point for both National Immunization Programs and office practice in developing countries with tropical climates ${ }^{2}$. At the end of the chain, primary health care providers must have adequate knowledge to manage the cold chain ${ }^{3}$. Several reports from developing countries indicate that health workers seem to be overwhelmingly concerned with only raising vaccination coverage. The quality of vaccination services that is equally important for achievement of the ultimate goal of disease reduction has been neglected. Suboptimal seroconversion rates and outbreaks of vaccine preventable diseases elsewhere were attributed to loss of vaccine potency either during transportation or storage $e^{4}$.

The objective of this study was therefore to assess the cold chain at primary health centers (PHC) and to 
assess the knowledge and the practices of medical officers at the $\mathrm{PHCs}$ regarding cold chain management in order to understand the gap in cold chain management as a contributing factor to the paradox between high vaccination coverage rates and the appearance of vaccine preventable diseases.

\section{Material and Methods}

\section{Study area}

The cold chain evaluation was conducted in Dakshina Kannada, a southern coastal district of Karnataka State, India. This district has an area of 4866 square kilometers and a population of 18, 97,730 (2001 census $)^{5}$. The district is served by a district hospital and 70 primary health centers. In the study district, $91.2 \%$ of children between 12-23 months are fully vaccinated with BCG, 3 doses of each of DPT and oral polio and measles vaccine ${ }^{5}$.

Assessment of the cold chain was conducted at all the PHCs of the district. Permission to include health centers for cold chain maintenance was obtained from the District Health Officer, who is responsible for overseeing health centers in the study district. Cold chain equipment and cold chain maintenance process was noted following direct observation by the investigator on uninformed visits. The evaluation instrument included information on demographics, electrically powered vaccine storage equipment (e.g., ice-lined refrigerators, deep freezers); non-electrical vaccine storage equipment (e.g., cold box, vaccine carriers); icepacks, power generators and temperature monitoring charts; assessment of the set-up and maintenance of electrical equipment.

In the second part of our study, knowledge and practice among medical officers of the PHCs about cold chain and immunization was assessed. Each PHC medical officer was requested to fill the structured and pretested questionnaire. The questionnaire included questions on background information of the respondents and more specific ones related to knowledge regarding management of the cold chain including the recommended storage temperature range, immunization schedules, use of diluents, storage in the deep freezers, measures to be taken in the event of power failure, the shake test and the effects of freezing vaccines.

\section{Results}

Seventy PHCs of the study district were visited and facilities for vaccine storage like ice lined refrigerator and deep freezers and facilities for vaccine transport like vaccine carriers and cold boxes etc were inspected. In addition temperature monitoring related issues was also noted.

Table 1 shows various facilities available for vaccine storage, transport and temperature maintenance in the PHCs of the study district. Seventy six medical officers of these PHCs were interviewed regarding the knowledge about vaccines, cold chain equipment, vaccine storage and temperature monitoring. Table 2 summarizes the knowledge of medical officers about different vaccines and cold chain management. Correct practices followed by PHC medical officers are shown in Table 3.

Table 1: Facilities available for vaccine storage in the PHC of the study district $(n=70)$

\begin{tabular}{|c|c|}
\hline Parameters & $\mathbf{N}(\%)$ \\
\hline \multicolumn{2}{|c|}{ Ice lined refrigerator } \\
\hline Available & $69(98.6)$ \\
\hline Not available & $1(1.4)$ \\
\hline \multicolumn{2}{|l|}{ Deep freezers } \\
\hline Available & $67(95.8)$ \\
\hline Not available & $2(2.8)$ \\
\hline Not functional & $1(1.4)$ \\
\hline \multicolumn{2}{|l|}{ Cold boxes } \\
\hline Available & $68(97.2)$ \\
\hline Not available & $2(2.8)$ \\
\hline \multicolumn{2}{|c|}{ Frozen ice packs } \\
\hline Available & $68(97.2)$ \\
\hline Not available & $2(2.8)$ \\
\hline \multicolumn{2}{|l|}{ Generator } \\
\hline Available & $66(94.2)$ \\
\hline Not available & $4(5.6)$ \\
\hline \multicolumn{2}{|c|}{ Automatic voltage stabilizers } \\
\hline Available & $68(97.2)$ \\
\hline Not available & $2(2.8)$ \\
\hline \multicolumn{2}{|c|}{ Dial thermometers } \\
\hline Available & $70(100)$ \\
\hline \multicolumn{2}{|c|}{ Temperature chart } \\
\hline Maintained & $66(94.2)$ \\
\hline Incomplete & $4(5.6)$ \\
\hline \multicolumn{2}{|c|}{ Vaccine storage in the refrigerator } \\
\hline Proper & $63(90)$ \\
\hline Not proper & $7(10)$ \\
\hline \multicolumn{2}{|c|}{ Presence of other items with vaccines } \\
\hline No & $60(85.7)$ \\
\hline Yes & $10(14.3)$ \\
\hline
\end{tabular}

Table 2: Correct Knowledge of PHC medical officers about vaccines, cold chain equipment, storage and monitoring $(n=76)$

\begin{tabular}{|l|r|}
\hline Parameter & \multicolumn{1}{|c|}{ N (\%) } \\
\hline Cold chain & $76(100)$ \\
\hline Universal Immunization Programme & $74((97.4)$ \\
\hline $\begin{array}{l}\text { Vaccines in Indian Academy of Paediatrics } \\
\text { immunization schedule }\end{array}$ & $57(75)$ \\
\hline
\end{tabular}




\begin{tabular}{|l|r|}
\hline Ideal Equipment & $74((97.4)$ \\
\hline Vaccines requiring diluents & $73(96.1)$ \\
\hline Time use of reconstituted vaccine & $44(57.9)$ \\
\hline Vaccine Vial Monitor & $61(80.3)$ \\
\hline Temperature monitoring & $46(60.5)$ \\
\hline Shake Test & $17(22.4)$ \\
\hline Vaccines available for polio & $70(92.1)$ \\
\hline
\end{tabular}

Table 3: Correct Immunization practices among PHC medical officers $(n=76)$

\begin{tabular}{|l|r|}
\hline Practices & N (\%) \\
\hline Immunization schedule practiced & $74(97.4)$ \\
\hline Rotation of vaccines & $74(97.4)$ \\
\hline Administration of OPV & $70(92.1)$ \\
\hline Pulse polio immunization & $71(93.4)$ \\
\hline Storage of diluents & $37(48.7)$ \\
\hline $\begin{array}{l}\text { Defrosting \& cleaning of Ice lined } \\
\text { refrigerator }\end{array}$ & $47(61.8$ \\
\hline Right steps in the event of power failure & $56(73.7)$ \\
\hline
\end{tabular}

\section{Discussion}

The cold chain still remains a highly vulnerable element of any immunization programme, both in developing and developed countries Careful attention to storage and handling is essential to ensure optimal potency of vaccines and to maximize the resulting efficacy of vaccination ${ }^{3}$. In India many studies have been conducted to assess the knowledge of health workers about vaccine vial monitor ${ }^{2,6,7,8,9}$. Studies assessing the knowledge and practice in various aspects of vaccine storage, administration are limited. Approach adopted in our study was multidimensional, not just the use of vaccine vial monitor, the other parameters involved in vaccination and cold chain were given equal importance and assessed.

Our study first focused on integrating the cold chain equipment and temperature monitoring related issues and discovered various irregularities in cold chain maintenance in Dakshina Kannada where infant mortality rate is low in comparison to other districts of Karnataka State ${ }^{5}$.

In the present study, facilities for vaccine storage like ice lined refrigerator and deep freezers were present in $98.6 \%$ and $95.8 \%$ respectively. Cold boxes, frozen packs and automatic voltage stabilizers were available in $97.2 \%$ of the PHC. Dial thermometers were present in all the centers

A study done by Samant et $\mathrm{al}^{2}$ revealed at $\mathrm{PHC}$ level $73 \%$ of the deep freezers, ice-lined refrigerators, and refrigerators were present and maintained the required temperature. Sixty five percent of the facilities adequately maintained the temperature-monitoring chart. Ninety-five percent of the vaccine carriers had adequately maintained temperatures. Eighty percent of the icepacks sampled at this level were in proper condition. Only $45 \%$ of the health centers had an electrical power generator, and $90 \%$ of these health centers reported frequent power failures. Availability of equipments like deep freezers, ice lined refrigerators, cold boxes, ice packs and electrical power generators was much higher in our study.

Despite the availability of deep freezers and ice lined refrigerators in majority of the centers, improper storage of vaccines was noticed in $10 \%$ in the present study. In a study from Ethiopia ${ }^{4}$, vaccine storage in the refrigerator was observed to be improper in $73.4 \%$ of the functioning centers. Inadequate air circulation between vaccine boxes and vaccines kept in the wrong compartment of the refrigerator were the major reasons for labeling storage improper.

Ideally, the storage equipment containing vaccines should not be used to store other products. However, our study showed that vaccines were sharing space with laboratory reagents, drugs in $14.3 \%$ of the centers. Galhotra et al in a study of surveillance of cold chain system during intensified pulse polio programme observed that $6.07 \%$ and $4.88 \%$ equipments were used for keeping food and drink in round 1 and 2 respectively ${ }^{6}$. This malpractice has also been reported by some other studies $^{3,10,11}$.

All the centers in our study had dial thermometers. Well maintained temperature record was seen in 94.2\% PHCs. However correct knowledge of time use of reconstituted vaccines was seen in only $57.9 \%$ of the medical officers. The correct practices of defrosting and cleaning the ice lined refrigerator and steps in the event of power failure were seen in $61.8 \%$ and $73.7 \%$ of the medical officers. A study has showed that in $6.2 \%$ of the centre there was no functional thermometer, in $33 \%$ of the centres proper temperature record was not maintained, in another $11.7 \%$ of the centres thermometer reading was outside the recommended range ${ }^{4}$. Therefore, even if the vaccines were potent on arrival at the health institutions, their potency could easily be compromised because of lack of proper monitoring of the cold chain system. Only $58 \%$ of the PHCs had necessary equipment to transfer vaccines in a study by Bachani et al ${ }^{12}$. In our study we found $97.8 \%$ of the health centers had adequate equipment to transfer vaccines which were near satisfactory.

In the present study, about $80.3 \%$ of the doctors were aware about the vaccine vial monitor. A study by Thakur et al in Chandigarh showed that only $67 \%$ of the 
vaccinators were aware of the vaccine vial monitor ${ }^{13}$. A study done in Delhi showed that $82 \%$ of the vaccinators were familiar with vaccine vial monitor ${ }^{14}$. As per a study done by Chudasma RK more than $51.6 \%$ of the staff members had not heard of vaccine vial monitor ${ }^{15}$. A study from two cities of Gujarat state during consecutive rounds of pulse polio immunization showed that correct knowledge of vaccine vial monitor among the booth workers varied from $46.1 \%$ to $93.3 \%$.

In our study majority of the PHC doctors had knowledge and correct practices in fields like ideal equipment, OPV administration, vaccine requiring the diluents but only $16 \%$ of PHC doctors were aware about the Shake test.

\section{Conclusions}

The availability of equipment is near universal in the present study. However the poor knowledge, for example, about the effect of freezing some vaccines, the shake test, the correct storage temperature range, steps in case of power failure and the observed inadequate vaccine storage practices, potentially may adversely affect the quality of the administered vaccines opening spaces for epidemics due to vaccine preventable diseases. We therefore recommend continuous training and supportive supervision as the key measures to address the findings of this study.

\section{Acknowledgement: None \\ Funding: None \\ Conflicting Interest: None \\ Permission from IRB: Yes}

\section{References}

1. Hinman A. Eradication of vaccine preventable diseases. Annu Rev Public Health 1999;20:211-29.

2. Samant Y, Lanjewar H, Parker D, Block L, Tomar GS, Ben Stein. Evaluation of the Cold-Chain for Oral Polio Vaccine in a Rural District of India. Public Health Rep 2007;122(1):112-21

3. Bankole $A M$, Olusegun KK, Marian NB, Godswill I, Adebowale OA, Lukeman AJS et al. The imact of health facility monitoring on cold chain management practices in Lagos, Nigeria. J Public Health Epidemiol 2010;2(4):78-81.
4. Berhane $Y$, Demissie $M$. Cold chain status at immunization centres in Ethiopia. East Afr Med J 2000; 77: 476-79.

5. Government of India. District Level Household and Facility Survey under Reproductive and Child Health Project (DLHS-3) District Fact Sheet 2007-08-Karnataka-DakshinaKannada available from - stg2.kar.nic.in/healthnew/NRHM/PDF/ Dakshina Kannada.pdf

6. Galhotra A, Goel NK, Pathak R, Kumar R, Swami HM. Surveillance of cold chain system during intensified pulse polio programme-2006 in Chandigarh. Indian J Paediatr 2007; 74(8):751-53.

7. Jain R, Sahu AK, Tewari S, Malik N, Singh S, Khare S et al.Cold chain monitoring of OPV at transit levels in India: correlation of VVM and potency status. Biologicals 2003; 31:237-44.

8. Aggarwal A, Singh AJ. Evaluation of cold chain system in rural areas of Haryana. Indian Paediatr 1995;32:31-4.

9. Chudasama RK. Evaluation of Intensive Pulse Polio Immunization in District Valsad During 2007. Indian Pediatr 2008;45:233-35.

10. Joao Carlos de TM, Gunnar B. Cold chain management: Knowledge and practices in primary health care facilities in Niassa, Mozambique. Ethiop. $J$ Health Dev 2007;21(2):130-35.

11. Bell KN, Hogue CJ, Manning C, Kendat A. Risk factors for improper vaccine Storage and handling in private provider offices. Paediatrics 2001;107: E100.

12. Bachani D, Bansal RD. Logistics management in Universal Immunization Programme. Indian J Public health 1990;34:179-84.

13. Thakur JS, Swami HM, Bhatia SP. Staff awareness of oral polio, Vaccine vial monitor in Chandigarh. Indian J Paediatr 2000;67:253-54.

14. Lal P, malhotra R, Gautam VP, Mehra M. assessment of functioning of pulse polio kendras and housu to house activity in Delhi: is there any scope for improvement? J Commun Dis 2003;35(4): 266-72.

15. Chudasma RK. Awareness about vaccine vial monitor at pulse polio booths. Indian Paediatr 2007;44:919-20.

\section{How to cite this article?}

Rao S, Naftar S, Baliga S, Unnikrishnana B. Evaluation, Awareness, Practice and Management of Cold Chain at the Primary Health Care Centers in Coastal South India. J Nepal Paediatr Soc 2012;32(1):19-22. 